\title{
O Psicólogo na Atenção Básica à Saúde
}

The Psychologist in the Basic Health Assistance

El Psicólogo en la Atención Básica a la Salud
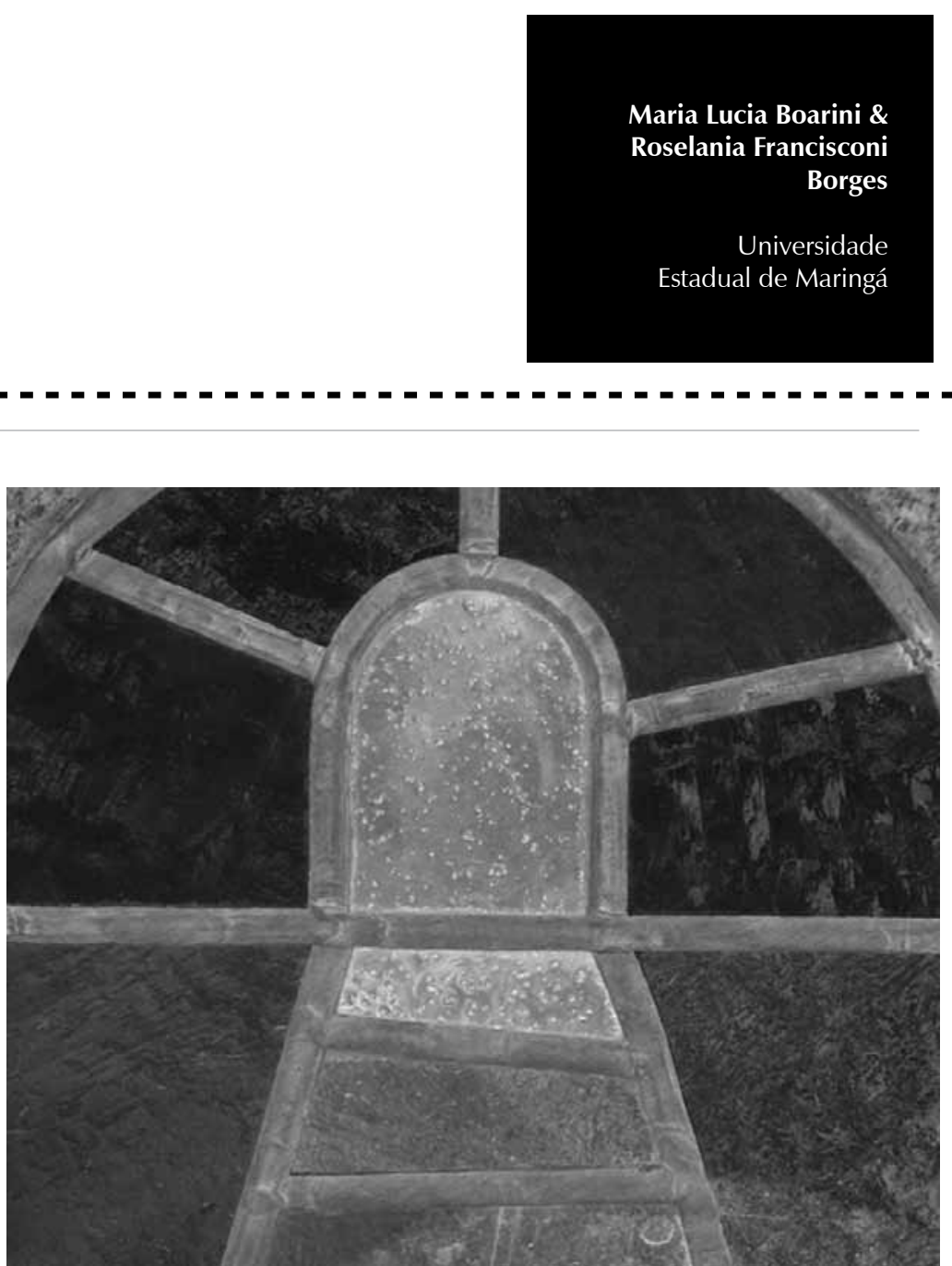
Resumo: O efetivo manejo dos transtornos mentais, nos serviços de saúde em geral, sobretudo na Atenção Básica de Saúde, é sem dúvida uma das exigências para viabilizar a desinstitucionalização do paciente psiquiátrico, com ou sem um longo histórico de várias internações. Nesse sentido, a preparação do profissional de saúde é uma prioridade na implementação da rede pública de saúde que, de fato, se proponha a atender a pessoa com transtorno mental em sintonia com os princípios da reforma psiquiátrica. Com essa orientação, estamos desenvolvendo, desde outubro de 2005, no Município de Itambé, PR, o projeto de extensão intitulado Formação do Psicólogo para Atuar em um Serviço Substitutivo (aos hospícios) de Atenção à Saúde Mental, que ora relatamos. Esse projeto se constitui em atividades desenvolvidas junto ao portador de transtorno mental e a seus familiares, aos profissionais da saúde e à comunidade em geral. Todas as atividades contam com a participação de acadêmicos devidamente inscritos no projeto. Os resultados até aqui alcançados nos permitem afirmar a pertinência de projetos dessa natureza como contribuição para a formação do psicólogo, e, na seqüência, para as mudanças necessárias à consolidação da reforma psiquiátrica. Palavras-chave: Formação do psicólogo. Transtorno mental. Reforma psiquiátrica. Atenção primária à saúde.

\begin{abstract}
The effective management of the mental disorders within the health services in general - especially at the Basic Health Assistance level - is no doubt one of the requirements for the deinstitutionalization of psychiatric patients, with or without a long hospitalization story. In this sense, the training of the health professional becomes a priority for the implementation of any public health care network that truly attempts to apply the principles of the psychiatric reform in caring persons with mental disorders. Under this guideline, we have been developing since October 2005, in Itambé (state of Paraná, Brazil), an extension project named Psychologist Training for Practice in Mental Health Care Replacement Services (in the mental hospitals), which we now describe. This project is made up of activities developed with mental patients, their families, health professionals and the community. All the activities have the participation of the students who are properly enrolled in the project. The results achieved thus far allow us to attest the significance of the projects of this nature as contributions to the training of psychologists, and subsequently, to the necessary changes for the consolidation of the psychiatric reform.
\end{abstract}

Keywords: Psychologist professional training. Mental disorder. Psychiatric reform. Primary health assistance.

Resumen: El efectivo manejo de los trastornos mentales, en los servicios de salud en general, sobretodo en la Atención Básica de Salud, es sin duda una de las exigencias para viabilizar a desinstitucionalización del paciente psiquiátrico, con o sin un gran histórico de varias internaciones. En ese sentido, la preparación del profesional de salud es una prioridad en la implementación de la red pública de salud que, de hecho, se proponga a atender la persona con trastorno mental en sintonía con los principios de la reforma psiquiátrica. Con esa orientación, estamos desarrollando, desde octubre de 2005, en el Municipio de Itambé, PR, el proyecto de extensión titulado Formación del Psicólogo para Actuar en un Servicio Sustitutivo (a los manicomios) de Atención a la Salud Mental, que ahora relatamos. Ese proyecto se constituye en actividades desarrolladas junto al portador de trastorno mental y a sus familiares, a los profesionales de la salud y a la comunidad en general. Todas las actividades cuentan con la participación de académicos debidamente inscritos en el proyecto. Los resultados hasta aquí alcanzados nos permiten afirmar la pertinencia de proyectos de esa naturaleza como contribución para la formación del psicólogo, y, en la secuencia, para los cambios necesarios a la consolidación de la reforma psiquiátrica.

Palabras clave: Formación del psicólogo. Trastorno mental. Reforma psiquiátrica. Atención primaria a la salud.

Este texto tem como objetivo socializar alguns dos resultados obtidos no desenvolvimento do projeto de extensão intitulado Formação do Psicólogo para Atuar em um Serviço Substitutivo (aos hospícios) de Atenção à Saúde Mental, que atualmente vem sendo realizado no Município de Itambé, no Estado do Paraná. Antes, porém, de focalizar o projeto propriamente dito e considerando que nosso foco de atenção é a formação profissional do psicólogo, seguiremos, a título de justificativa, desse foco com algumas notas a respeito.

É fato que, desde a regulamentação e a institucionalização dos cursos de Psicologia, em 1962, a formação do psicólogo tem sido fonte de preocupação de alguns profissionais desse campo de conhecimento. Entretanto, é a partir dos anos 80 do século XX, por conta do fim do regime militar e das novas necessidades sociais, que se acirram os questionamentos 
sobre a formação do psicólogo e, na seqüência, a atuação desse profissional. Entre as várias questões colocadas em discussão, ocuparam lugar de destaque a pouca atenção dada pelo psicólogo às demandas das classes populares. Destacouse, ainda, a atuação desse profissional junto às classes sociais que tinham condições de buscar apoio em consultórios particulares. Em síntese, avolumaram-se as críticas à tendência hegemônica de atuação do psicólogo, centrado no caráter privatista e individualizante de atendimento. Após um amplo processo de debates entre as instituições de ensino superior, foi apresentada ao Conselho Nacional de Educação, pela Comissão de Especialistas, uma proposta de diretrizes curriculares para a graduação em Psicologia, entre outras medidas, que a aprovou em 2001, com algumas modificações. Esse fato gerou controvérsias e estimulou novos e importantes debates. Para não nos distanciarmos do objetivo deste texto, não prosseguiremos nesta discussão a respeito das diretrizes curriculares ${ }^{1}$, mas é necessário pontuar que as entidades profissionais, sobretudo os Conselhos Federal e Regionais de Psicologia, vêm participando ativamente desse movimento em prol da revisão e da reformulação dos cursos de Psicologia. Dentre as inúmeras questões sobre esse assunto, circunscrevemos nossa atenção ao que se refere à formação do psicólogo para atuar no Sistema Único de Saúde. Nesse sentido, destacamos uma das propostas apresentada e aprovada no I Fórum Nacional de Psicologia e Saúde Pública, realizado em Brasília de 20 a 22 de outubro de 2006, no qual foi recomendado que se viabilizassem esforços visando a

${ }^{1}$ São inúmeras as publicações e documentos sobre o assunto, dentre os quais sugerimos o periódico Revista do Departamento de Psicologia - UFF, 14(1), 2002.
Continuar o diálogo com os órgãos competentes para que sejam implantados, junto às agências formadoras em Psicologia, mecanismos que promovam maior integração entre o SUS e as instituições de ensino superior, através das atividades de ensino, pesquisa e extensão em políticas públicas de saúde. (Conselho Federal de Psicologia [CFP], 2006, p 27)

Nesse evento, propôs-se também a integração dos projetos de ensino, pesquisa e extensão em saúde coletiva e políticas públicas nas instituições de ensino superior a fim de "efetivar a inserção do estudante na rede de atenção à saúde... valorizando estratégias concretas, flexíveis e inovadoras de atuação interdisciplinar" (CFP, 2006, p. 32).

Vale lembrar que, nos debates ocorridos nos anos 80 do século passado, as discussões acerca da formação do psicólogo e de suas ações profissionais não aconteceram isoladamente. Foi um importante período da história do Brasil, em que vários setores da sociedade brasileira se mobilizaram para avaliar os rumos que até então estavam sendo seguidos depois de "um longo e tenebroso" governo ditatorial, em que a mudez era a única atitude permitida. Nos inúmeros debates ocorridos após a ditadura militar, o setor da saúde pública destacou-se pela presença e pela força dos argumentos. Data de 1986 a realização da histórica VIII Conferência Nacional de Saúde, fórum importante que está na origem do Sistema Único de Saúde, regulamentado pelas leis no $8080 / 90$ e no 8142/90. Por conta dos reclamos da sociedade brasileira e como desdobramento da VIII Conferência Nacional de Saúde, é realizada em Brasília, DF, em 1987, a I Conferência Nacional de Saúde Mental. Grande número de psicólogos militantes no âmbito da saúde mental, afinados com os movimentos sociais de base popular, compareceu, dando o tom e a cor a esse histórico evento do campo da saúde mental. Registra-se nessa época também o Il Congresso Nacional de Trabalhadores de Saúde Mental, realizado em 1987, na cidade de Bauru, no Estado de São Paulo, que introduziu o lema Por uma sociedade sem manicômios. 
São esses alguns dos fatos históricos mais importantes que serviram de mola propulsora para a mudança da hegemonia do modelo liberal e privatista do profissional psicólogo, "responsável por seu isolamento autoengendrado", como afirma Botomé (1979). Vale destacar que essa tendência hegemônica de formação com ênfase no modelo médico e o quase total desconhecimento da rede pública de saúde, não só da Psicologia, mas também de várias profissões da área da saúde, vêm sendo questionadas também por órgãos internacionais. No que tange a atenção à saúde mental, a Organização Pan-Americana de Saúde e a Organização Mundial de Saúde (OPAS/OMS, 2001), por exemplo, recomendam aos países em desenvolvimento que aprimorem a formação de profissionais de maneira que possam apoiar programas de atenção primária de saúde, como se segue:

Investir tempo e energia na avaliação do número e dos tipos de profissionais e trabalhadores necessários nestes próximos anos com a integração da atenção em saúde mental no sistema de saúde geral aumentará a demanda de generalistas com treinamento em saúde mental.... Assim, a saúde mental deve ser incluída nos programas de formação com cursos de atualização destinados a melhorar a efetividade no manejo de transtornos mentais nos serviços de saúde gerais. (OPAS/OMS, 2001)

\section{O projeto de extensão}

Com essa referência e em sintonia com o importante e histórico debate acerca da formação do psicólogo, iniciamos, em 2004, o projeto de extensão objeto desta reflexão em duas unidades básicas de saúde da rede pública de saúde do Município de Maringá, no Estado do Paraná, sob a supervisão local das respectivas psicólogas dessas unidades. Trata-se de um projeto de extensão universitária elaborado de acordo com as disposições determinadas pela Universidade
Estadual de Maringá. Tais disposições definem a extensão universitária como "o processo educativo, cultural e científico que articula o ensino e a pesquisa de forma indissociável, desenvolvendo ações direcionadas para o atendimento das demandas da comunidade" (Universidade Estadual de Maringá, 1997).

No Município de Maringá, o projeto foi realizado durante dois anos. Por razões de caráter administrativo e em virtude do afastamento, por licença médica e mudança de Município, das psicólogas das unidades básicas de saúde onde se realizava o projeto, este foi encerrado em Maringá, tendo tido continuidade em Itambé, também no Estado do Paraná. A seguir, são passadas algumas informações sobre esse Município e o relato do projeto propriamente dito.

\section{O Município de Itambé e sua rede de saúde pública}

Pelo fato de ser considerado um Município de pequeno porte, Itambé conta apenas com um serviço de saúde, composto de uma unidade básica de saúde, duas equipes do Programa de Saúde da Família e um hospital geral público, com capacidade para 25 leitos, que atende os casos de baixa complexidade. Os casos de média e alta complexidade são encaminhados aos serviços de saúde de Maringá. Em termos de recursos humanos na área de saúde mental, Itambé conta com uma psicóloga em regime de trabalho em tempo integral (40 horas semanais).

No que tange à área de saúde mental, até 2003, os casos identificados eram encaminhados diretamente ao Hospital Psiquiátrico de Maringá, PR, uma instituição privada, ou ao Hospital Psiquiátrico de Jandaia do Sul, PR, uma instituição pública. Após 2003, com a inauguração da Emergência Psiquiátrica em Maringá, esses casos passaram a ser encaminhados para esse equipamento, 
por exigência de lei. Aliás, pelo fato de não existir um acompanhamento e a identificação ocorrer apenas em face de agravo do transtorno mental (surto), a internação psiquiátrica era efetuada na maioria dos casos.

A partir do ano 2006, mediante parceria com a Universidade Estadual de Maringá, segundo as características deste projeto de extensão, essa situação começou a ser modificada.

\section{O projeto de extensão no Município de Itambé}

Este projeto de extensão tem como objetivos gerais: 1) atualizar o acadêmico de Psicologia no que tange ao atendimento extra-hospitalar dirigido aos portadores de transtorno mental e 2) formar recursos humanos para atuar em um serviço substitutivo aos hospitais psiquiátricos para atendimento ao portador de transtorno mental. Está aberto para a participação de acadêmicos de Psicologia do segundo ano em diante.

Entendemos que o investimento na formação do psicólogo para atuar na atenção básica dando prioridade ao atendimento da pessoa com transtorno mental, com ou sem histórico de internações recorrentes, é uma possível e necessária contribuição para a inversão do modelo manicomial ainda presente no Brasil. Com o acompanhamento na Atenção Básica à Saúde, é possível um significativo controle da ocorrência do agravo do transtorno mental, ou surto psicótico. Dessa forma, evita-se o isolamento do indivíduo de seu grupo social bem como se favorece a desmistificação da idéia de periculosidade pelo convívio cotidiano com a comunidade. Tal investimento nos coloca em consonância com as recomendações da OPAS/OMS (2001) de proporcionar tratamento na atenção primária e envolver as comunidades.

\section{Metodologia}

As atividades desenvolvidas contemplam todos os segmentos do Município, a saber: os profissionais de saúde, os usuários e suas famílias e a comunidade em geral, considerando que todos os nomeados estão envolvidos no processo saúde-doença.

Os acadêmicos, por sua vez, participam de todas as atividades desenvolvidas sob a supervisão local da psicóloga responsável pelo setor de saúde mental do Município em questão.

Todas as atividades desenvolvidas são discutidas uma vez por mês entre os acadêmicos, a psicóloga do Município e a coordenação do projeto, para avaliar os rumos do trabalho que está sendo desenvolvido e corrigi-los, se necessário. No final de cada ano letivo, os resultados são apresentados, em forma de relatório, à Pro-Reitoria de Extensão da Universidade Estadual de Maringá, mantenedora deste projeto.

Apresentaremos, a seguir, todas as atividades desenvolvidas na vigência deste projeto, bem como seus objetivos. Para facilitar a exposição às atividades, serão apresentadas em forma de itens:

\section{1- Capacitação dos técnicos e profissionais} da saúde em geral (agentes comunitários, enfermeiros, médicos, dentistas e demais funcionários) da Rede Pública de Saúde do Município. No início do projeto, foram promovidas reuniões que serviram de capacitação para a comunidade em geral. Dessas reuniões, participaram conselheiros municipais, representantes dos poderes legislativo e executivo municipal, pastoral da saúde, profissionais da educação e grupo da terceira idade. Tal atividade teve como objetivo desmistificar informações já cristalizadas no imaginário popular e socializar as informações acerca do direito 
da pessoa portadora de transtorno mental, que pressupõe o favorecimento de ações mais adequadas aos princípios da reforma psiquiátrica. Para tanto, são desenvolvidos encontros pré-programados com temas determinados, oficinas, etc.;

\section{2- Atuação junto ao portador de transtorno mental e suas famílias, com o objetivo de} aproximá-los dos serviços de saúde. Além disso, contribuir para melhor compreensão do transtorno mental tanto da parte do portador quanto do seu grupo familiar, investir na recuperação da autonomia do usuário, que, geralmente, fica deveras prejudicada após a experiência de reclusão em hospitais psiquiátricos. Essa atividade é desenvolvida por meio de encontros semanais, nos quais se promove discussão geral em grupo, produção de artesanato, organização de passeios, comemorações, teatro informativo, canto coral, etc. Todas as atividades já desenvolvidas neste item foram registradas em forma de relatórios, listagem de presença e foram ilustradas com vídeos e fotos da ocasião. Essas fotos e vídeos têm um significado especial, pois, além de representar a memória do projeto, são utilizadas como tema para algumas atividades propostas.

\section{3- Participação da avaliação diagnóstica por} meio de informações e acompanhamento contínuo do usuário e de seus familiares. Essa atividade tem o objetivo de orientar e apoiar o portador de transtorno mental bem como sua família quanto ao uso de medicação, cuidados com a saúde e eventuais encaminhamentos a outras especialidades, como, por exemplo, oftalmologia, odontologia, etc.

\section{3- Visitas domiciliares às famílias de pessoas portadoras de transtornos mentais -sejam eles desconhecidos ou já acompanhados pelo serviço - com o objetivo de favorecer o estreitamento dos vínculos entre os novos usuários dos serviços públicos de saúde e os profissionais ou consolidar os}

já existentes. Essa ação, além de possibilitar o conhecimento e o acompanhamento da demanda reprimida do Município, possibilita também a organização de um quadro situacional dos usuários das unidades de saúde envolvidas. As visitas são estimuladas pelos agentes comunitários de saúde/ACS ou pela ausência continuada do portador de transtorno mental ou de seus familiares aos encontros semanais.

4- Atendimento individual, quando for indicado.

Além de todos os registros efetuados durante as reuniões, no final de 2008, quando se completaram dois anos de vigência deste projeto, solicitamos uma avaliação por escrito de todos os envolvidos. Alguns desses depoimentos ilustrarão os resultados a seguir. O critério para a visibilidade de alguns depoimentos foi a freqüência da apresentação de determinados conteúdos.

\section{Resultados}

O número crescente de portadores de transtorno mental e de seus familiares participantes dos encontros semanais nos dois anos de vigência deste projeto, a nosso juízo, pode ser interpretado como um dos resultados significativos. Embora o projeto tenha sido oficializado em outubro de 2005, conseguimos reunir usuários e familiares e promover o primeiro encontro em fevereiro de 2006. Na ocasião, iniciamos com 23 pessoas. Desse primeiro encontro, até novembro de 2008, tivemos alguns desligamentos motivados por diferentes fatores (mudança de cidade, morte, acidente) e novas adesões. Ainda assim, o número de participantes foi crescente. O encontro realizado em novembro de 2008 contou com a participação de 40 pessoas.

Além desses números, os registros realizados durante os encontros semanais e a avaliação 
"...Com os

atendimentos e com o projeto presente, os pacientes passam a retornar às suas atividades do cotidiano, passam a conviver com outras pessoas, os incluindo novamente na sociedade em que vivem (enfermeira PSF, equipe 01). solicitada no final de 2008 revelam alguns resultados e estimulam algumas reflexões.

Em relação aos familiares, fica clara a sobrecarga que possuem em relação ao membro da família que sofre psiquicamente: "É muito difícil. É difícil fazer ele ficar tranqüilo, eu não faço nada que deixe ele nervoso, deixo ele ficar na liberdade dele" (mãe de V., 33 anos, com diagnóstico de esquizofrenia) ou: "Quando ele não está bem, eu fico muito aflita. Eu fico com medo, pois sei que ele tá sofrendo. Eu tenho medo, tem hora. Nenhuma mãe quer ver o filho sofrer..." O futuro também contribui para a sobrecarga: "Eu sonho de ver ele animado, e sobre quando eu partir, deixar ele bem, em um estado que não vai sofrer" (mãe de A., 25 anos, com diagnóstico de esquizofrenia). Sobre a participação nos encontros semanais proporcionados pelo projeto, os familiares revelam que "teve uma grande melhora. Ele era muito quieto e não saía de casa. Hoje ele vai, e se sente feliz o dia que ele vai. Ele já fica falando: 'tal dia vai ser dia da nossa reunião'. Hoje ele já levantou cedo, tomou banho, fez barba e logo foi" (mãe de V., 33 anos, com diagnóstico de esquizofrenia). "Senti ele mais saído, mais dado com as pessoas. Depois que ele começou a freqüentar o grupo, ele tá mais espontâneo, se dá mais com as pessoas" (mãe de A. 25 anos, com diagnóstico de esquizofrenia). Dessa forma, vimos observando que os familiares se sentem mais apoiados na busca de ajuda para a pessoa que sofre psiquicamente.

No que tange aos profissionais de saúde, constatamos que passaram a reconhecer o Serviço de Atenção Básica em Saúde Mental do Município como o primeiro encaminhamento a ser dado a esses pacientes. Isso significa que estão se convencendo de que o usuário deve ser acompanhado no Município independentemente de estar em crise, inclusive sendo assistido quanto ao uso de medicamentos, consultas periódicas da saúde em geral ou outras necessidades básicas de saúde. A avaliação do projeto solicitada a esses profissionais no final de 2008 atesta essa afirmação: “...Com os atendimentos e com o projeto presente, os pacientes passam a retornar às suas atividades do cotidiano, passam a conviver com outras pessoas, os incluindo novamente na sociedade em que vivem (enfermeira PSF, equipe 01).

Sim, é importante que continue o projeto, porque há uma formação de vínculos do portador de transtorno mental com profissionais de Psicologia, dessa forma se torna uma porta de entrada para o tratamento médico e a atuação de outros profissionais da saúde juntamente a esse paciente. (enfermeira PSF, equipe 02)

“...O projeto colabora de forma positiva para a inclusão social e a reabilitação psicossocial desses portadores, justificando a necessidade de sua continuidade para o Município" (farmacêutica).

Frente a tais afirmações, constatamos que, aos poucos, vão abandonando as velhas práticas que sustentam o atendimento à pessoa com transtorno mental e, na seqüência, dando sinais de uma visão mais racional:

(o projeto) Contribui muito, pois temos que encaminhar os pacientes para outro Município para ter o tratamento, e nem sempre a cidade tem meios de transporte para levar os pacientes deixando o tratamento. Com as psicólogas na cidade (refere-se aos acadêmicos), o tratamento não pára, e o paciente melhora e segue sua vida da melhor maneira possível. O Município necessita da continuidade desse projeto, pois o tratamento é feito na cidade, sem gasto para mandar para outra cidade, e o tratamento é contínuo. (auxiliar de enfermagem PSF, equipe 02)

Na perspectiva do portador de transtorno mental, temos observado maior preocupação com a aparência pessoal e com a saúde em geral, inclusive buscando entender o seu diagnóstico médico. Não é incomum o 
descaso com a saúde geral após o diagnóstico de transtorno mental. Bem a gosto da perspectiva cartesiana e por conta dos problemas advindos do quadro psicopatológico, os cuidados com o corpo são esquecidos, como se existissem separadamente. Neste projeto, trabalhamos no sentido de abandonar essa dicotomia. A Tabela 1 indica os encaminhamentos estimulados e realizados a partir dos encontros semanais do projeto para especialidades médicas.

Tabela 1 - Encaminhamentos a serviços de saúde.

\begin{tabular}{lccc}
\hline Especialidades & 2007 & 2008 & Total \\
\hline Odontologia & 05 & 04 & 09 \\
Clínica geral & 28 & 26 & 54 \\
Psiquiatria & 18 & 26 & 44 \\
Oftalmologia & 02 & 02 & 04 \\
Dermatologia & 01 & 03 & 04 \\
Ginecologia & 06 & 05 & 11 \\
TOTAL & 60 & 66 & 126 \\
\hline
\end{tabular}

Fonte: Secretaria Municipal de Saúde, 2009.

1. Estes dados se referem àqueles registrados nos prontuários médicos da unidade básica de saúde, mas podem ter ocorrido outros encaminhamentos sem o conhecimento da equipe, feitos por médicos plantonistas em atendimento no hospital do Município ou com agendamento pelo sistema privado de saúde.

2. Os dados da psiquiatria se referem tanto às consultas iniciais quanto às consultas periódicas.

Nas atividades desenvolvidas em grupo, notamos maior disposição do portador de transtorno mental para participar de demandas sociais, como as reuniões propostas, comemorações de aniversário, etc., tal como afirma J., 39 anos: "Fiquei mais animado. Tenho onde sair de vez em quando".

Em geral, demonstram maior possibilidade de elaborar planos e ter expectativas, construir ou estreitar laços de amizades decorrentes do convívio com os demais participantes, além de poder estabelecer vínculos de confiança com os profissionais que atuam junto a ele: "Gosto do grupo. Conheci muitas pessoas: o O., o A., a dona R., todas pessoas bem legais. Só não conheço aquela moça que quase não vem, nem sei o nome dela....Todos muito amigos" (V., 33 anos, com diagnóstico de esquizofrenia). E, claro, sem perder de vista que há um problema que exige um acompanhamento médico:

A psicóloga disse que eu tenho a esquizofrenia. Eu acho ruim ter, porque de vez em quando eu fico sofrendo, tendo umas neuras esquisitas ...tomo medicação e também o Bem-me-quer (é a autodenominação do grupo que se encontra semanalmente) ajuda a melhorar. Melhora a cabeça no dia a dia, comecei a me relacionar melhor com as pessoas, a ser compreensivo, e melhorou pra mim.

(V., 33 anos, com diagnóstico de esquizofrenia)

Em relação aos acadêmicos, notamos que perdem o medo de estar perto de pessoas com transtorno mental ao reconhecerem que eles são seres humanos como todos os outros, que essas pessoas têm família, casa, desejos e necessidades, com histórias de vida recheadas de sonhos e também de mágoas e perdas. Elas percebem que a internação retira o portador de transtorno mental de suas próprias referências e não o ajuda a lidar com suas questões do cotidiano; dão sinais de preocupação com as necessidades gerais da pessoa com transtorno mental, pois a vêem no dia a dia, e não somente em poucas e curtas passagens durante as visitas às instituições psiquiátricas, 
como geralmente acontece na tradicional formação acadêmica, e sentem que o trabalho é delicado e deve ser contínuo, com olhar diferenciado e sensível.

Alguns dos depoimentos de acadêmicas que participaram deste projeto confirmam nossa avaliação:

De modo mais específico, as visitas domiciliares permitiram a ampliação da minha visão de doença mental, muitas vezes limitada às conceituações teóricas versadas nos livros de psicopatologia. Além disso, através de tal atividade, foi possível verificar a necessidade de esses pacientes e seus familiares serem assistidos por um programa de atendimento que lhes permita não apenas um maior conhecimento da doença mental e das formas de se lidar com ela, mas também que lhes propicie um espaço para serem sujeitos, para construírem a palavra e serem ouvidos. (Maia, 2007, p. 31)

Com a participação no projeto, perdi o receio em conviver, conversar com alguém com esse histórico, desmistificando a imagem de "louco", além de aprender muito mais do que vemos em sala de aula, tanto no que é realmente um transtorno mental para o sujeito e sua família e como funciona na prática o sistema de saúde substitutivo aos manicômios, como de forma geral funciona a saúde mental pública. (Santos, 2009, p. 30)

Todas as atividades que realizamos no projeto são muito gratificantes e muito enriquecedoras, cada uma de nós que fazemos parte deste projeto temos uma oportunidade única de nos aproximar dos chamados transtornos mentais e ter uma visão mais humana em relação a eles, ficarmos mais próximas das pessoas portadoras e nos familiarizarmos com a prática da Psicologia, por isso considero de grande valia a participação neste projeto, assim como o que ele tem a nos oferecer quanto conhecimento, prática, sensibilização, etc. (Dantas, 2008, p. 30)

\section{"Nem tudo o que reluz é ouro"}

Os avanços alcançados não podem ser traduzidos como ausência de dificuldades, pelo contrário. As dificuldades existem e são variadas, confirmando o adágio popular que nos serve de subtítulo. São vários os exemplos, dos quais destacamos a distância da moradia de alguns pacientes da zona rural, muitos dos quais residem a muitos quilômetros da unidade básica de saúde, situação agravada pela falta de iniciativa de alguns pacientes para comparecer às reuniões, e, quando nas reuniões, por conta da sua autonomia já bastante fragilizada, têm dificuldades para participar das atividades propostas em grupo. Essa indisposição da pessoa com transtorno mental, de certa forma, pode ser justificada pelo uso de medicação ultrapassada, que produz sérios efeitos colaterais. Esse não comparecimento do paciente e/ou seu familiar às atividades sugeridas provoca, via de regra, a necessidade de freqüentes visitas familiares. Por sua vez, a realização dessas visitas é dificultada pela falta de veículos da Secretaria da Saúde disponíveis para essas atividades. Como agravante, temos a falta de uma equipe interdisciplinar com tempo hábil para participar de todas as ações necessárias, principalmente do médico psiquiatra, para participar do diagnóstico, prescrever e acompanhar a medicação do paciente junto ao demais profissionais. Vale ressaltar que tais dificuldades e tantas outras que não foram aqui nomeadas, salvo erro de generalização, não são exclusivas deste projeto de extensão. Temos por hipótese que são pertinentes à rede pública de saúde do Município em referência, quiçá de qualquer outro Município do Brasil. Registramos, ainda, a dificuldade de deslocamento do estagiário por se tratar de um Município distante 40 km da universidade, e, quando o acadêmico se dispõe a essa viagem, nos deparamos com a incompatibilidade de horário da grade curricular, o que dificulta ainda mais o desenvolvimento de trabalhos dessa natureza em Municípios distantes, de pequeno porte e com poucos recursos. São essas algumas das dificuldades que enfrentamos e que, em geral, provocam rebatimentos no desenvolvimento deste projeto. 


\section{"Apesar de você, amanhã há de ser outro dia"}

Parafraseando o talentoso compositor brasileiro Chico Buarque e à guisa de finalização, podemos afirmar que, apesar das dificuldades, os depoimentos traduzidos como resultado nos revelam que estamos no caminho do "amanhã", do "outro dia" ou de outra forma de perceber e atender a pessoa que sofre psiquicamente. Projetos dessa natureza podem contribuir para tanto, e a formação de psicólogos orientados para a atuação em saúde pública, principalmente no nível de Atenção Básica à Saúde, é fundamental. Neste projeto, priorizamos atitudes como escuta e acolhimento, em situações de urgência ou não, estimulamos os contatos necessários para o estabelecimento da relação de confiança, de vínculos que possibilitem a diminuição do sofrimento psíquico vivenciado tanto pelo paciente quanto pelas pessoas que fazem parte das suas relações familiares. Trabalhamos no sentido de desmistificar a arraigada idéia que habita o imaginário popular de que "lugar de louco é no hospício". São gestos aparentemente simples que não fazem parte de manuais de psiquiatria ou de Psicologia, mas têm evitado a consolidação de quadros psiquiátricos de difícil controle, para os quais a saída tem sido a contenção hospitalar na condição de exclusão social. Essa medida tem sido historicamente comprovada como ineficaz, porquanto apenas transforma em crônico um problema mental que talvez pudesse ser episódico, se atendido de outra forma.

Nessa perspectiva, nada mais ilustrativo do que relembrar as memórias do importante escritor brasileiro Lima Barreto, que viveu muitos anos em um hospital psiquiátrico e nesse local morreu. Suas reflexões foram escritas há quase um século, mas não apresentam uma ruga sequer: "Aqui no hospício, com as suas divisões de classe, de vestuário, etc., eu só vejo um cemitério"... mas assim e assados, a loucura zomba de todas as vaidades e mergulha todos no insondável mar de seus caprichos incompreensíveis... Debruçar sobre o mistério dela e decifrá-la parece estar acima das forças humanas... (Barreto, 2004).

Se, lá no final do século XIX e nas primeiras décadas do século $X X$, o isolamento da pessoa com transtorno mental se justificava como "medida de proteção", em nossos dias, esse é um argumento anacrônico. Com os avanços do conhecimento nessa área e a disponibilidade da psicofarmacologia, não há mais argumentos eficientes para isolar a pessoa com transtorno mental do seu meio social. O convívio na comunidade possibilita a visibilidade social e desmistifica a idéia da periculosidade da loucura e de que ela está circunscrita apenas ao indivíduo.

Isso não significa que estejamos negando o transtorno mental ou, mais que isso, simplificando o atendimento a essa questão. O transtorno mental, apesar dos avanços no conhecimento das diferentes áreas, como já assinalamos anteriormente, ainda constitui um desafio e um processo em construção no que se refere à compreensão e à forma de atendê-lo. Dentre tantos percalços que ainda precisam ser equacionados, além da gênese do transtorno mental propriamente dito, que continua sendo um enigma para a ciência, há que se considerar a efetividade da rede de atendimento a situações de urgência-emergência nas grandes cidades e o desempenho do componente de saúde mental na atenção básica. Assim, sabemos que a implementação da política de saúde mental depende integralmente da participação de todos e do debate democrático de seus desafios e limitações, portanto, a agenda da saúde mental no pacto da saúde deve 
ser construída coletivamente e reforçar a participação do Município na condução dessa política. E, nesse processo, o acadêmico de Psicologia tem um lugar importante. Por essa razão, esse acadêmico deve se preparar para reconhecer o transtorno mental como possibilidade para todos, deve se preparar para buscar novas formas de encaminhamento e abandonar a idéia de que o isolamento em hospital psiquiátrico seja a solução para a pessoa que está em sofrimento mental. Enfim, o acadêmico de
Psicologia, e tantos outros da área da saúde, tem o compromisso de aprender a lidar com essa situação sem aceitar o decreto de morte civil dado às pessoas portadoras de transtornos psíquicos. Em relação à pessoa que está em sofrimento psíquico, todos temos o compromisso de buscar formas de tirá-la da crise que a atormenta, e não a sua liberdade de ir e vir, e isso os acadêmicos de Psicologia que participaram deste projeto parecem já ter assimilado.

Maria Lucia Boarini*

Doutora, docente do Departamento de Psicologia e do Programa de Pós-Graduação do

Departamento de Psicologia da Universidade Estadual de Maringá.

Roselania Francisconi Borges

Mestre em Psicologia. Psicóloga da Secretaria Municipal de Saúde do município de Itambé-PR.

E-mail: r_oselaniafborges@uol.com.br

*Endereço para envio de correspondência:

Universidade Estadual de Maringá, Departamento de Psicologia

Avenida Colombo, 5790, bloco 118 - Maringá - PR - Brasil, CEP: 87020-000

E-mail: mlboarini@uol.com.br 
Barreto, A. H. de L. (2004). O cemitério dos vivos: memórias. São Paulo: Planeta; Rio de Janeiro: Fundação Biblioteca Nacional.

Botomé, S. P. (1979). A quem nós, psicólogos, servimos de fato? Psicologia, ano 5(1), 1-15.

Conselho Federal de Psicologia. (2006). I Fórum Nacional de Psicologia e Saúde Pública - Relatório Final. Brasília, DF: Autor.

Dantas, S. H. (2008). Relatório parcial do processo $n^{\circ}$ 0204/06 PRE. Maringá, PR: Universidade Estadual de Maringá.

Maia, P. M. (2007). Relatório parcial do processo $n^{\circ}$ 0204/06 PRE. Maringá, PR: Universidade Estadual de Maringá.

Ministério da Saúde (2006, novembro/dezembro). Reestruturação da assistência psiquiátrica hospitalar no SUS: balanço e agenda 2007. Saúde Mental no SUS: Informativo da Saúde Mental. Área técnica da SM/DAPE/SAS/MS, Brasília, ano 5(24).
Santos, I. S. (2009). Relatório parcial do processo $n^{\circ}$ 0204/06 PRE. Maringá, PR: Universidade Estadual de Maringá.

Organização Pan-Americana da Saúde/Organização Mundial da Saúde. (2001). Relatório sobre saúde no mundo-saúde mental: nova concepção, nova esperança (Escritório central da Oficina Pan-Americana de Saúde, Trad.; área técnica de saúde mental do Ministério da Saúde do Brasil, Rev.). Brasília, DF.

Universidade Estadual de Maringá. (1999). Resolução n. ${ }^{\circ}$ 093/99-CEP. Maringá, PR: Conselho Ensino e Pesquisa da Universidade Estadual de Maringá. 